\title{
Fuzzy-PID in BLDC Motor Speed Control Using MATLAB/Simulink
}

\author{
Hari Maghfiroh ${ }^{1 *}$, Musyaffa' Ahmad ${ }^{2}$, Agus Ramelan ${ }^{3}$, Feri Adriyanto ${ }^{4}$ \\ 1, 2,3,4 Department of Electrical Engineering, Universitas Sebelas Maret, Surakarta, Indonesia \\ Email: ${ }^{1}$ hari.maghfiroh@ staff.uns.ac.id, ${ }^{2}$ musyaffaahmad10@gmail.com, ${ }^{3}$ agusramelan@ staff.uns.ac.id, \\ ${ }^{4}$ feri.adriyanto@staff.uns.ac.id \\ *Corresponding Author
}

\begin{abstract}
Brushless DC motors (BLDC) are one of the most widely used types of DC motors, both in the industrial and automotive fields. BLDC motor was chosen because it has many advantages over other types of electric motors. However, in its application in the market, most of the control systems used in BLDC motors still use conventional controls. This conventional method is easy and simple to apply, but has many weaknesses, one of it is that if the system state changes, then the parameters of the PID must also be changed, so that static and dynamic performance will decrease, causing slow response and frequent oscillations. In this study, the design and simulation of a speed control system for BLDC motors using the Fuzzy-PID method was carried out. The research method is performed through simulation with Matlab / Simulink. The simulation is carried out by providing a speed set point of $650 \mathrm{rpm}$ and used two methods, namely Fuzzy-PID and PI. The test results show that the FuzzyPID control can provide better and more stable performance than the conventional PI control. The use of Fuzzy-PID control can reduce speed fluctuation and give torque stability. In the stator current and back EMF (Electromotive Force), Fuzzy-PID has more stable current and voltage than PID which make smaller losses. Furthermore, the proposed method, Fuzzy-PID has faster processing time compared to PID by $6.27 \%$.
\end{abstract}

Keywords-BLDC Motor, PID, Fuzzy-PID

\section{INTRODUCTION}

Brushless DC motors (BLDC) are among the most widely used DC motors, both in the industrial and automotive fields. BLDC motors are like and consequently called Permanent Magnet DC Synchronous motors [1]. This type of DC motor does not have a brush and commutator, so BLDC motors require less maintenance and can operate quieter than DC motors [2]. The initial cost of the motor may seem expensive but generally diminishes with time [3]. Due to the special characteristic, the BLDC motor is very common in various industrial and biomedical, and robotic applications which require high torque to weight ratio and precise position control for accuracy [4]. BLDC motor was chosen because it has the characteristics of high efficiency, reliability, wide speed range, large torque, and small power [5][2]. Therefore, it has great theoretical and practical significance to do a lot of research about the brushless DC Motor structure and its controller [6][7].

There are some different control schemes used for the BLDC motor speed control [8]. The control system on a BLDC motor is quite complicated by using several electronic components that are arranged to be able to switch between the three motor phases with precision [9]. There are two types of speed control systems, namely the Open-Loop system and the Closed-Loop system. An open Loop system is a control system whose output has no effect on controlling the action and there is no feedback [10]. On the other side, the BLDC motor control system on the market already uses a closedloop control system that has a feedback mechanism.

In the market application, most control method in BLDC motors still use conventional controls such as PI (Proportional-Integral) and PID (Proportional-IntegralDerivative) [4] [11]. This conventional control method was chosen because of its simple structure and easy operation [9]. However, this control method still has many weaknesses, such as if the system state changes, the PID parameters must also be changed, so that the static and dynamic performance will decrease, causing slow response and frequent oscillations [12]. Several studies have been developed to produce a reliable and optimal BLDC motor control system. One of the control methods used is fuzzy logic control. This method was chosen because it has the reliability to solve complex and nonlinear problems, is flexible to various problems, and can be combined with other control methods to produce a more optimal system [5].

This research will design and simulate a speed control system for BLDC motors using the Fuzzy-PID method. This test is intended to determine the performance of using Artificial Intelligence, especially Fuzzy Logic in its application in electric motors. Fuzzy logic is used to generate PID parameters $(K p, K i$, and $K d$ ) which are then forwarded to the PID to produce a more reliable and optimal control system. The test results are then compared using the conventional PI method in order to obtain which method is best used to control the BLDC motor speed.

\section{MATERIAL AND METHOD}

\section{A. BLDC Motor}

The BLDC motor is a type of permanent magnet synchronous motor, which has a permanent magnet in the rotor and a trapezoidal back-electromotive force (EMF) [13]. BLDC motor has the characteristics of a DC machine by replacing the mechanical commutator and brush with a solidstate switch and there is no electrical connection between the stator and the rotor [14]. BLDC motor construction is shown in Fig. 1.

BLDC motors are widely used in various electronic components, especially in electric vehicles. This is because BLDC motors have various advantages over other motors, namely wide torque range, high speed, high efficiency, good 
dynamic response, strong, no-slip, and others [14]. The motor specification that used in this research is described in Table 1.

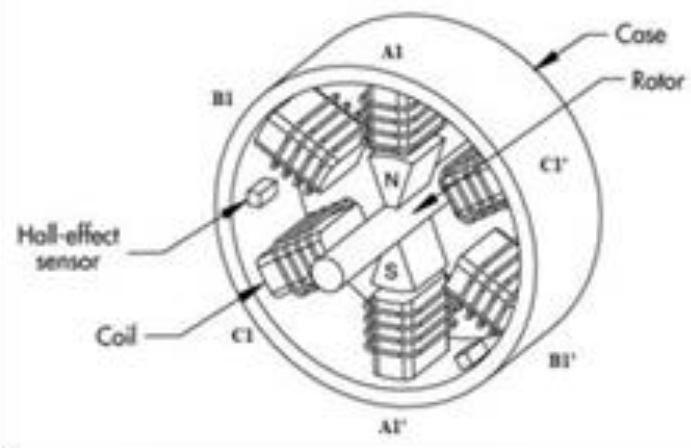

Fig. 1. BLDC Motor Construction [7]

TABLE I. BLDC MOTOR SPECIFICATION

\begin{tabular}{cc}
\hline Specification & Value \\
\hline Voltage & $48 \mathrm{~V}$ \\
Power & $1 \mathrm{~kW}$ \\
Speed Max & $700 \mathrm{RPM}$ \\
\hline
\end{tabular}

The electrical part of the system is governed by equation (1) [15]:

where,

$$
V_{d c}=i R+L \frac{d i}{d t}+E
$$

$$
\begin{array}{ll}
V d c & =\text { voltage applied in DC } \\
L & =\text { winding inductance } \\
R & =\text { winding Resistance } \\
E & =\text { back emf of the motor }
\end{array}
$$
equation as:

$$
T_{e}=J \frac{d \omega}{d t}+B \omega+T_{L}
$$

where,

$$
\begin{array}{ll}
T e & =\text { Electromagnetic torque in } \mathrm{Nm} \\
J & =\text { Moment of inertia } \\
\omega & =\text { Angular speed } \\
B & =\text { Friction coefficient } \\
T_{L} & =\text { Load torque }
\end{array}
$$

\section{B. Various BLDC Control Scheme}

Several studies have been conducted to combine the Fuzzy control system with other control systems for application in BLDC motor drives. Some of the studies that have been carried out are as resumed in Table 2 .

TABLE II. VARIOUS FUZZY BASED CONTROL SCHEME

\begin{tabular}{cccc}
\hline Ref & Year & Control & Methods \\
\hline$[16]$ & 2017 & $\begin{array}{c}\text { Fuzzy Sliding } \\
\text { Mode } \\
\text { Controller } \\
\text { Particle Swarm } \\
\text { Optimized } \\
\text { Fuzzy Logic } \\
\text { Controller }\end{array}$ & $\begin{array}{c}\text { Constant of Sliding Mode } \\
\text { Control law is varied by } \\
\text { Fuzzy Logic Controller } \\
\text { Torque control of BLDC } \\
\text { motor based on PSO and } \\
\text { Fuzzy Logic controller. }\end{array}$ \\
\cline { 3 - 4 } & 2017 & $\begin{array}{c}\text { Fuzzy controller based on } \\
\text { Controller }\end{array}$ & $\begin{array}{c}\text { Funtinuity intelligent } \\
\text { weight function. }\end{array}$
\end{tabular}

[23] 2013

\section{[25] $2011 \quad$ Extended}

Kalman Filter (EKF) - Fuzzy-

Neural -

Network

Controller

[26] 2011 Sliding Mode

Control and

fuzzy control scheme.
Parallel Fuzzy

PID Controller

Emotional learning based Neuro-Fuzzy

Controller

Genetic

Algorithm

(GA) based

Fuzzy

Controller

[30] 2001 Adaptive Neuro

- Fuzzy

Inference

System

(ANFIS)
Methods

Type-2 Fuzzy allows to

model the effects of

uncertainty in the rule based fuzzy system.

Fuzzy consolidated sliding mode controller with moving weight condition. PSO based scale factor parameters in offline optimization for reduced tuning time

Hybrid System Combining Advantage of

Compensation Logic and Neural Network

PID tuning by Sliding mode fuzzy for chattering elimination \& improved response

Fuzzy pre-compensator is used to modify controller to compensate output variation

EKF filters the noise in the error and delta error and prevents controller to process noise at cost of delayed response

Control efforts proportional to distance from sliding surface for chattering dismissal

Three parallel Fuzzy subcontroller that update the value of PID gains online

Supervisory learning algorithm (as Critic) controls the network behavior

GA based optimization and Online tuning of fuzzy parameters for robust performance.

Neuro structured learning algorithm find appropriate fuzzy logic rule, then parameter learning algorithm to fine tune membership function and other parameters

Some of research in the Table 2 above, have prove that Fuzzy Logic Controller (FLC) can work as well with the other control methods. The combination of FLC with the other methods give some benefit such as increasing the efficiency, effectivity, performances and accuration of the test result. However, the combination cannot applicated in all of plant, so the combination should be adjusted with the plant used. 


\section{Fuzzy Logic Controller}

Fuzzy Logic is a branch of Artificial Intelligence (AI) that has been used since 1965 until now. Fuzzy is still chosen because of its reliability to solve complex and nonlinear problems, its flexibility to various problems and can be combined with other control methods to produce a more optimal system [5]. Fuzzy logic uses basic rules to produce fuzzy output, namely the IF-THEN rule, where IF is an antecedent and THEN is a consequence [31]. In the fuzzy method, there are 4 main components, namely [5]:

- Fuzzifier: Fuzzifier is used to map the value / price of variables in the real world into fuzzy sets.

- Knowledge base: The knowledge base contains control system knowledge as a guide for evaluating the state of the system to obtain control output as desired by the designer.

- Fuzzy inference engine: Fuzzy inference engine translates fuzzy statements in the rule base into mathematical calculations (fuzzy combinational).

- De-Fuzzification: Defuzzification can be defined as the process of changing Fuzzy quantities which are presented in the form of output Fuzzy sets with a membership function to regain their crisp form.

The block diagram of the Fuzzy control system can be observed in Fig. 2.

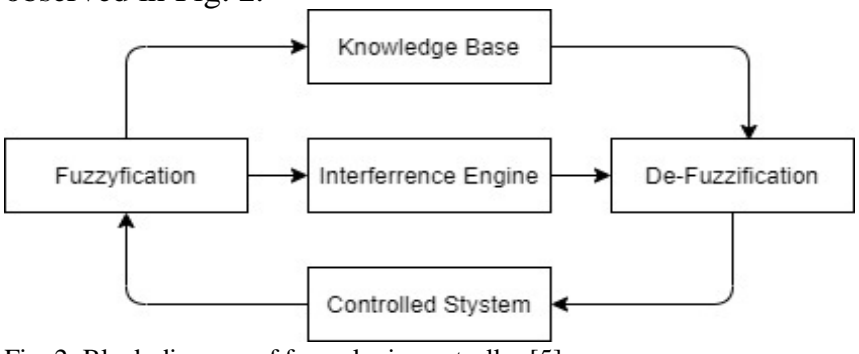

Fig. 2. Block diagram of fuzzy logic controller [5]

\section{Fuzzy-PID Block Diagram}

The block diagram of the Fuzzy-PID control can be seen in Fig. 3. In this structure, 3 Fuzzy Logic Control blocks are used, each of them has the same input, namely error and delta-error. Meanwhile, the output of each fuzzy block is $K p$, $K i$ and $K d$. This output is then processed using the PID control to adjust the output voltage from the power source that supplies the BLDC motor.

Since there is five fuzzy membership for each input; therefore, the fuzzy rules used are 25 rules. These rules can be seen in Table 3. Where DB: Decrease Big; DS: Decrease Small; NC: No Change; IS: Increase Small and IB: Increase Big. While the set of membership functions of the input variables (error and delta error) can be observed in Fig. 4 and Fig. 5.

TABLE I. BLDC MOTOR SPECIFICATION

\begin{tabular}{|c|c|c|c|c|c|}
\hline elde & NB & NS & $\mathbf{Z}$ & PS & PB \\
\hline NB & DB & DB & DB & DS & NC \\
\hline NS & DB & DB & DS & NC & IS \\
\hline $\mathbf{Z}$ & DB & DS & NC & IS & IB \\
\hline PS & DS & NC & IS & IB & IB \\
\hline PB & NC & IS & IB & IB & IB \\
\hline
\end{tabular}

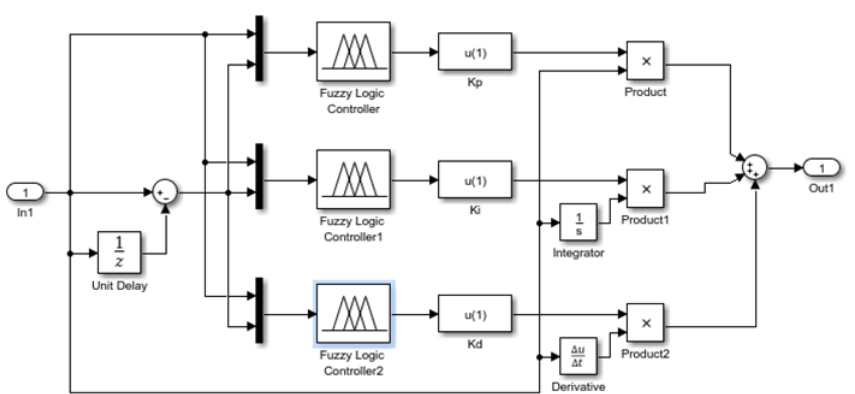

Fig. 3. Block diagram of Fuzzy-PID

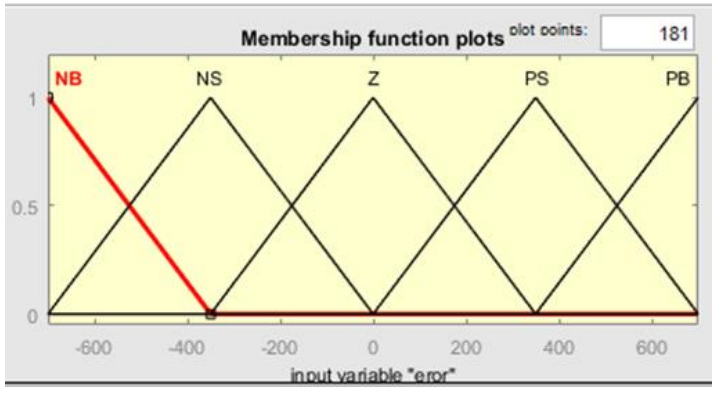

Fig. 4. Membership Fungtion of error input

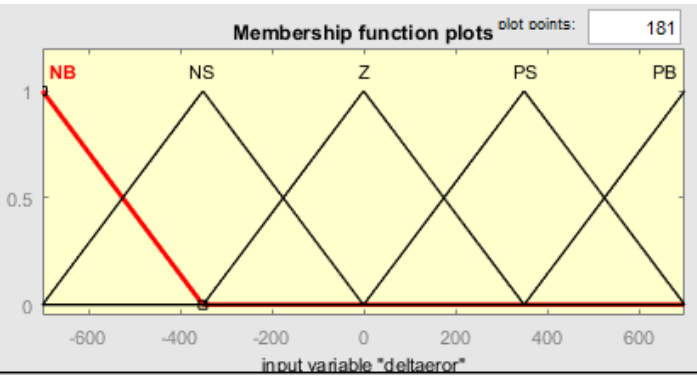

Fig. 5. Membership Fungtion of delta-error input

The Fuzzy block diagram for output of $K p, K i$ and $K d$ are shown in Fig.6, Fig.8 and Fig. 10, respectively. Whereas, Fig.7, Fig.9 and Fig. 11 shows the Membership function of output $K p, K i$ and $K d$ respectively.

- $\quad$ FLC for Kp

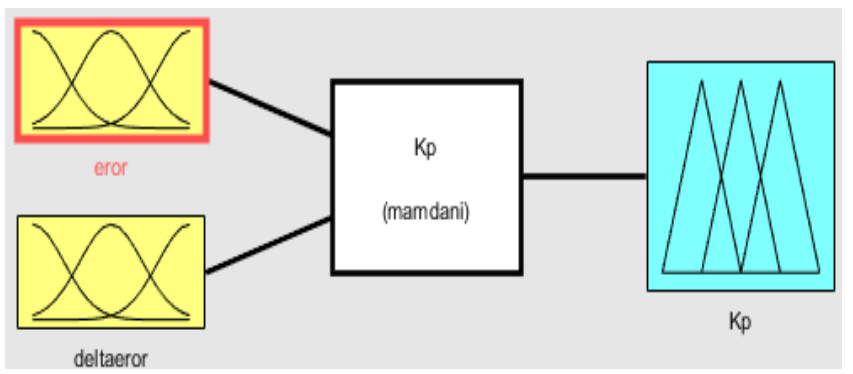

Fig. 6. Block fuzzy for Kp output

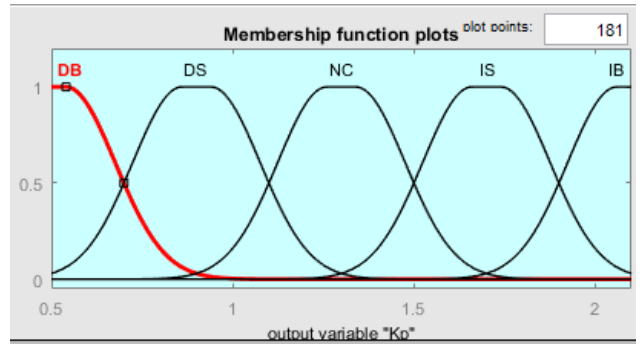

Fig. 7. Membership function of Kp output 


\section{- $\quad$ FLC for Ki}

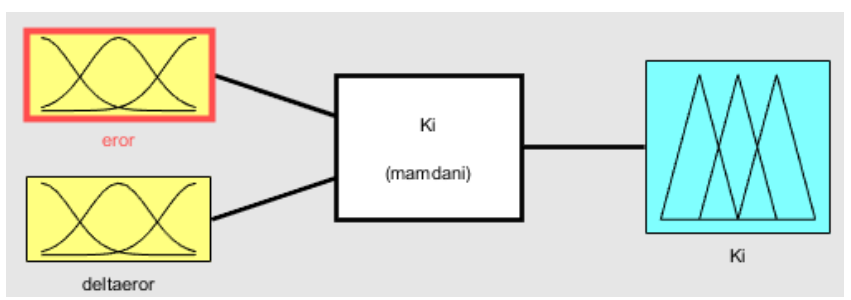

Fig. 8. Block fuzzy for Ki output

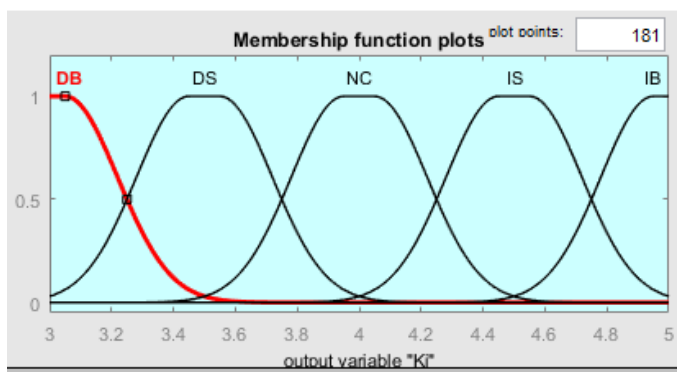

Fig. 9. Membership function of Ki output

- $\quad$ FLC untuk Kd

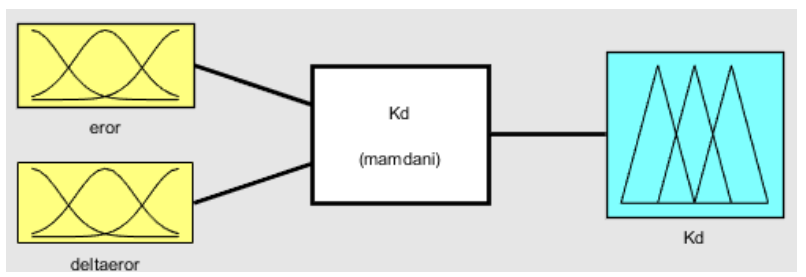

Fig. 10. Block fuzzy for Kd output

\section{RESULT AND DISCUSSION}

The simulation is carried out by providing a speed set point at $650 \mathrm{rpm}$. The simulation was carried out by comparing two methods, namely Fuzzy-PID and the conventional PI method. The plant of this circuit is a brushless DC motor (BLDC) $48 \mathrm{~V} 1 \mathrm{~kW}$ with a maximum speed of 700 rpm. Fig. 12 shows the simulation block of the proposed Fuzzy-PID control method in MATLAB Simulink.

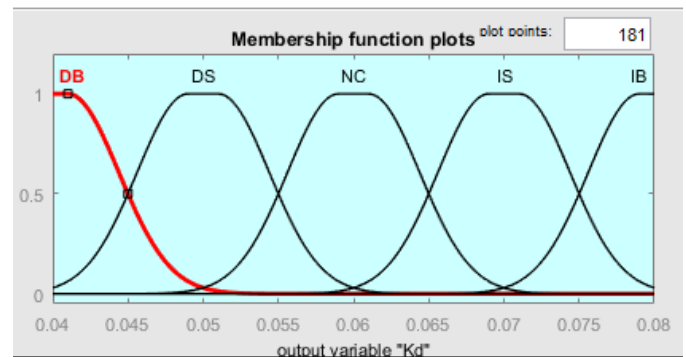

Fig. 11. Membership function of Kd output

Based on Fig. 13, it can be observed that the Fuzzy-PID control is able to provide a good response to reach the desired set point. By using the Fuzzy-PID method, steady-state speeds can be achieved at 0.3 seconds without significant overshoot and fluctuation. On the other side, the conventional PI method can reach a steady-state point at 0.2 seconds but with very high fluctuations and experiencing overshoot up to $180 \mathrm{rpm}$.

In the electromagnetic torque, Fig. 14 shows that the FuzzyPID method produces a stable torque graph, where the torque decreases with the increasing speed of the motor. The torque reaches a constant point at $5 \mathrm{Nm}$ when the motor reaches a steady-state speed. While the PI method provides an unstable graph of torque with high enough fluctuation and overshoots up to $35 \mathrm{Nm}$ before the steady-state speed is reached.

Fig. 15 shows that the current and back voltage resulted from Fuzzy-PID is quite stable during the motor operation. In contrast, when using the PI method, there are fluctuations in the current and reverse voltage EMF on the stator. This resulted in system instability and resulted in a lot of losses.

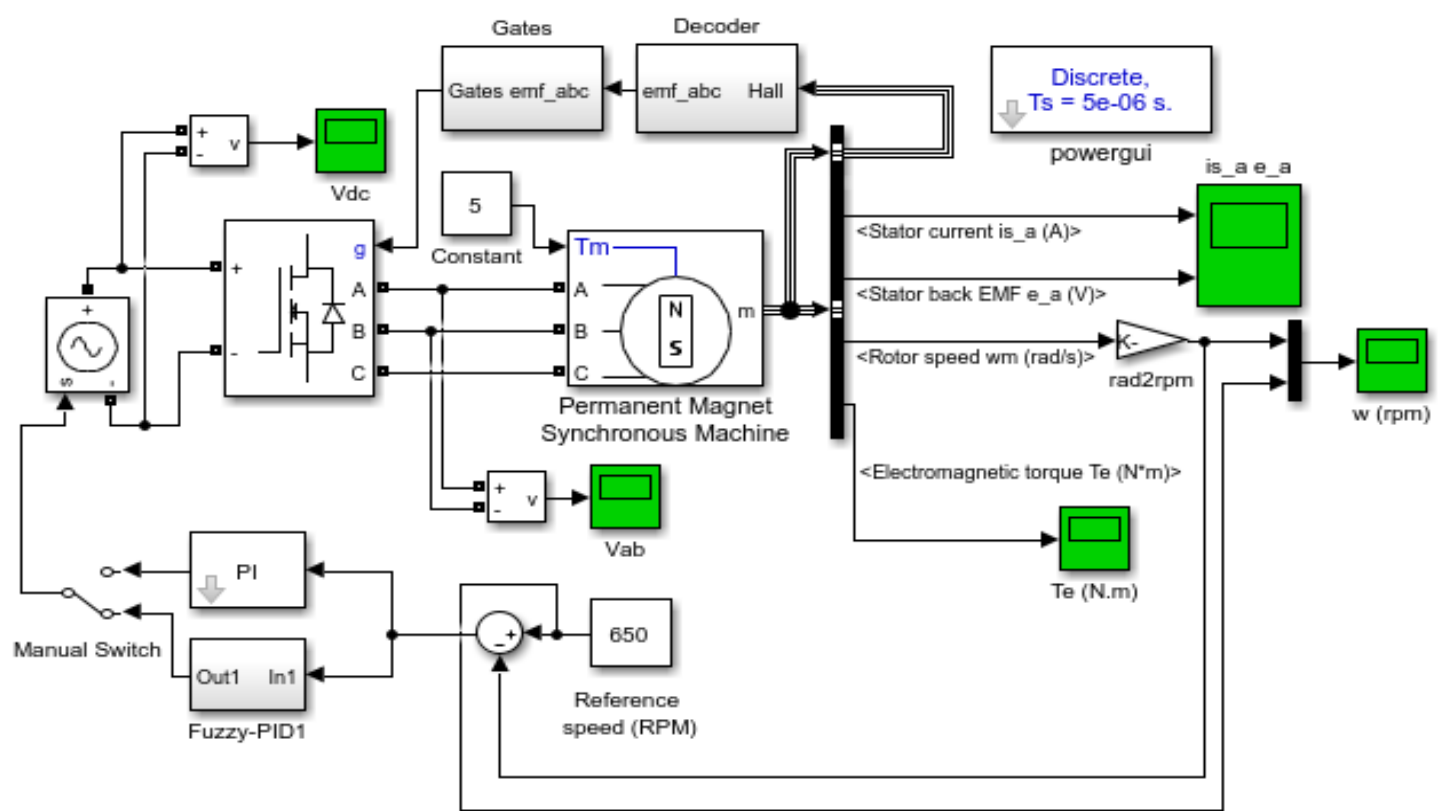

Fig. 12. Fuzzy-PID BLDC Control in MATLAB Simulink 


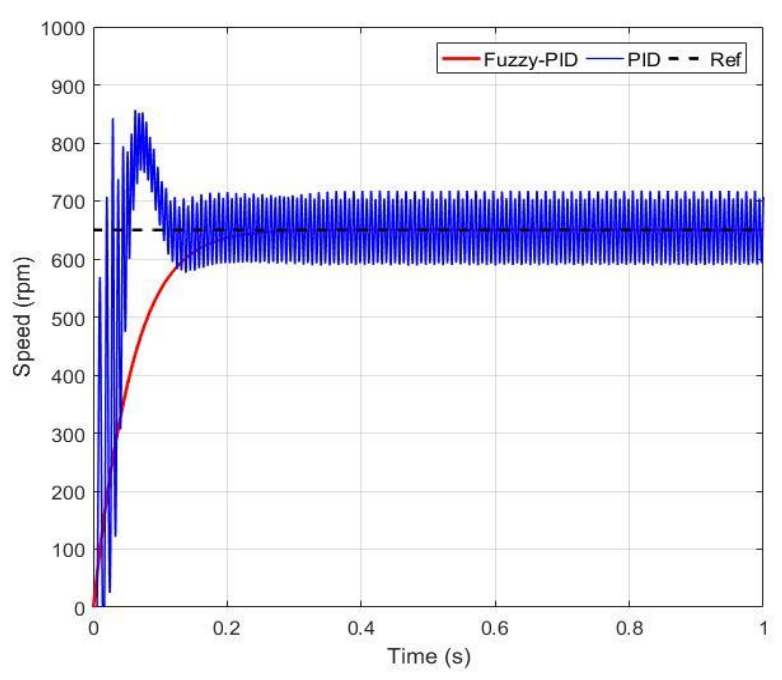

Fig. 13. Speed profile

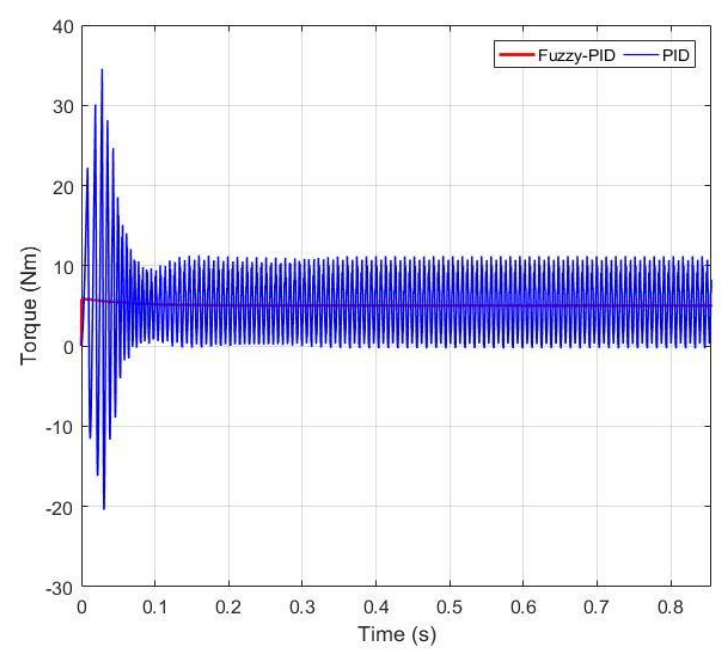

Fig. 14. Electromagnetic torque
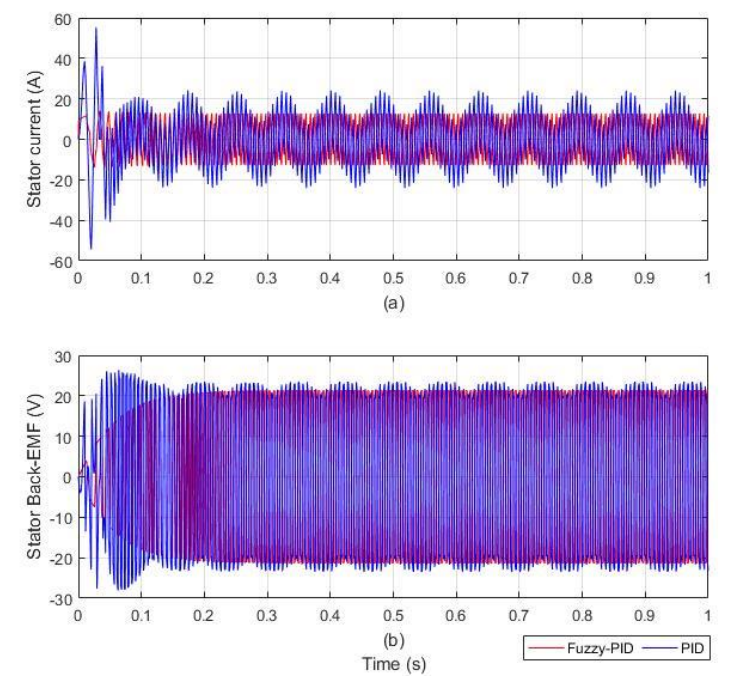

Fig. 15. Stator Current \& Back EMF

The simulation time for each method is resumed in Table IV. It clearly shown that Fuzzy-PID has faster processing time compared to PID by $6.27 \%$. Therefore, the overall result show that Fuzzy-PID is better than PID.

TABLE II. BLDC MOTOR SPECIFICATION

\begin{tabular}{cc}
\hline Method & Simulation Time (s) \\
\hline Fuzzy-PID & 29.58 \\
PID & 31.56 \\
\hline
\end{tabular}

\section{CONClusions}

The design and simulation of the Fuzzy-PID control system on BLDC speed control have been successfully carried out. Based on the simulation, the Fuzzy-PID control can provide better and more stable speed performance than using the conventional PI control. The use of Fuzzy-PID control can reduce speed fluctuation and give better torque stability so that the BLDC motor can operate more reliably. In the stator current and back EMF, Fuzzy-PID has more stable current and voltage than PID which make smaller losses. Furthermore, the proposed method, Fuzzy-PID has faster processing time compared to PID by $6.27 \%$.

\section{ACKNOWLEDGMENT}

This paper was supported by Multi Years Program of PNBP Research Grant from Universitas Sebelas Maret with the contract numbers: 452/UN27.21/PN/2020, and 260/UN27.22/HK.07.00/2021. We would like to thank to IoT Laboratory Faculty of Engineering Universitas Sebelas Maret.

\section{REFERENCES}

[1] A. Fitzgerald, C. Kingsley, and S. Umans, Electric Mac1ullery. ser. Electrical Engineering Series, McGraw-Hili Companies, Incorporated, 2002.

[2] M.S. Aspalli, M.M. Farhat, and L.M. Savitri, "Speed control of BLDC Motor with Four Switch Three Phase Inverter using Digital Signal Controller", 2015 International Conference on Power and Advanced Control Engineering (ICPACE). Bangalore, India, 2015.

[3] J.J. Rath QHS (T), "Effective Speed Control in 3-Phase BLDC Motor by Reaching Law based Sliding Mode Technique", International Journal of Computer Application. Volume 43, No.16, April 2012.

[4] P.H.Y. Sheng, X. Wang, and L. Wang, "Fuzzy PID Control Syatem Design of Brushless DC Motor Based on Vector Control," Chinese Automation Congress, pp. 5583-5587, 2017.

[5] R. Goswami and J. Dheeraj, "Performance Review of Fuzzy Logic Based Controllers Employed in Brushless DC Motor," International Conference on Computational Intelligence and Data Science (ICCIDS), 2018.

[6] Z. Hao, "Brushless DC can intellegent controller of research and simulation implementation," Hubei: Wuhan University of Technology, 2009 .

[7] W. Zhou and X. Zhang, "Double Closed Loop Sliding Mode PID Control System for BLDCM of Pure Electric Vehicle," Proceedings of the 35th Chinese Control Conference, pp.4730-4734, July 2016.

[8] U. Ansari, S. Alam, and S.M.u.N. Jafri, "Modelling and Control of Three Phase BLDC Motor using PID with Genetic Algorithm," UK Sim 13th International Conference on Modelling and Simulation, 2011, pp.189-194.

[9] M. Ahmad, "Development of Speed Control and Monitoring System in BLDC Motor with Hall Sensor," Final Project, Electrical Engineering Department of Universitas Sebelas Maret Surakarta, 2020.

[10] K. Ogata, Translation of Automatic Control Techniques (Regulatory System) Vol 1. Erlangga, Jakarta, 1995.

[11] U. Maheshwararao, Y.S. Kishorebabu, and K. Amaresh, "Sliding Mode Speed Control of DC Motor", International Conference on 
Communication Systems and Network Technologies, 2011.

[12] Y. Xiaojuan and L. Jinglin, "A Novel Sliding Mode Control for BLOC Network Control System, " 3rd international Conference on Advanced Computer Theory and Engineering, 2010.

[13] M.J. Prabu, P. Poongodi, and K. Premkumar, "Fuzzy Supervised Online Coactive Neuro-Fuzzy Inference System-Based Rotor Position Control of Brushless DC Motor," IET Power Eelctronics Journal, 2016, pp. 1-11.

[14] R.B. Ashok and B.K. Mahesh, "Comparative Analysis of BLDC Motor For Different Control Topology," 1 st International Conference on Power Engineering, Computing and Control, (PECCON) VIT University, Chennai Campus, 2017.

[15] V. Nigam, S. Hussain, and S. N. Agarwal, "A Hybrid Fuzzy Sliding Mode Controller for a BLDC Motor Drive," 1st IEEE International Conference on Power Electronics, Intelligent Control and Energy Systems, pp. 1-4, 2016.

[16] K.M.A. Prasad and U. Nair, “An Intelligent Fuzzy Sliding Mode Controller for a BLDC Motor," International Conference on Innovative Mechanisms for Industry Applications, pp. 274-278, 2017.

[17] S. Agrawal and V. Shrivastava, "Particle Swarm Optimization of BLDC Motor With Fuzzy Logic Controller for Speed Improvement," 8th International Conference on Computing Communication and Network Technology, pp. 1-5, 2017.

[18] H. Wang, Y. Shu, P. Li, and D. Kang, "Double Closed Loop Control for BLDC Based on Whole Fuzzy Controllers," 2nd International Conference on Computational Intelligence and Application, pp. 487491, 2017.

[19] I. F. Davoudkhani, "Adaptive Speed Control of Brushless DC (BLDC) Motor Based on Interval Type-2 Fuzzy Logic," 24th Iranian Conference on Electrical Engineering, pp. 1119-1124, 2016.

[20] V. Nigam, S. Hussain, and S.N. Agarwal, "A Hybrid Fuzzy Sliding Mode Controller for a BLDC Motor Drive," 1st IEEE International Conference on Power Electronics, Intelligent Control and Energy Systems, pp. 1-4, 2016.

[21] Z. Wang, C. Liu, X. Song, Z. Song, and Z. Yang, "Improved Variable Universe Fuzzy Pid Application In Brushless Dc Motor Speed Regulation System," International Conference on Machine Learning and Cybernetics, South Korea, pp. 459-463, 2016.
[22] G. Deying and Z. Jinquan, "Speed control of BLDCM Based on Compensated Fuzzy Neural Network," T he 26th Chinese Control and Decision Conference (2014 CCDC), pp. 4541-4544, 2014.

[23] C. Navaneethakkannan and Dr.M. Sudha, "Comparison of Conventional \& PID Tuning of Sliding Mode Fuzzy Controller for BLDC Motor Drives," International Conference on Computer Communication and Informatics, pp. 4-9, 2013.

[24] V. Verma, V. Harish, and R. Bhardwaj, "Hybrid PI Speed Controllers for Permanent Magnet Brushless DC Motor," 5th India International Conference on Power Electronics, pp. 1-5, 2012.

[25] A. Rubaai and P. Young, "EKF-Based PI/PD-Like Fuzzy-NeuralNetwork Controller for Brushless Drives," IEEE Trans. Ind. Appl., vol. 47, no. 6, pp. 2391-2401, 2011.

[26] C.S.R. Reddy and M.S. Kalavathi, "Improved Performance of a Novel SMC-Fuzzy Controller for DTC Brushless DC Motor Drive for Precise Speed Regulation," 9th International Conference on Power Electronics and Drive, pp. 873-880, 2011.

[27] A. Rubaai, M. J. Castro-sitiriche, and A.R. Ofoli, "Design and Implementation of Parallel Fuzzy PID Controller for HighPerformance Brushless Motor Drives: An Integrated Environment for Rapid Control Prototyping," IEEE Trans. Ind. Appl., vol. 44, no. 4, pp. 1090-1098, 2008.

[28] A. H. Niasar, A. Vahedi, and H. Moghbelli, "Speed Control of a Brushless DC Motor Drive via Adaptive Neuro-Fuzzy Controller Based on Emotional Learning Algorithm," International Conference on Electrical Machines and Systems, Vol. 1, pp. 230-234, 2005.

[29] C. Xia, P. Guo, T. Shi, and M. Wang, "Speed Control of Brushless DC Motor Using Genetic Algorithim Based Fuzzy Controller," International Conference on Intelligent Mechatronics and Automation, China, pp. 460-464, 2004.

[30] Ushakumari, S. Sankaran, R. Nair, and P.S Chandramohanan, "Adaptive Neuro-Fuzzy Controller for Improved Performance," International Fuzzy Systems Conference, pp. 493-496, 2001.

[31] H.U. Jianyao, W.U. Juan, H. Peng, Q. Peng, and Q. Huang, Application of Fuzzy Logic Algorithm for Optimization of Control Strategy in Electric Vehicles (IEEE), 2017. 